\title{
Calcifying cystic odontogenic tumor associated with an odontome - a diverse lesion encountered
}

This article was published in the following Dove Press journal:

Clinical, Cosmetic and Investigational Dentistry

31 July 2015

Number of times this article has been viewed

Chourasia Radheshyam'

Bandyopadhyay Alokenath ${ }^{2}$

Harish Kumar ${ }^{2}$

Panda Abikshyeet ${ }^{2}$

'Shri Medishine Hospital, Raipur, Chhattisgarh, India; ${ }^{2}$ Department of Oral and Maxillofacial Pathology, Kalinga Institute of Dental Sciences, KIIT University, Bhubaneswar,

Odisha, India
Correspondence: Panda Abikshyeet Department of Oral and Maxillofacial Pathology, Kalinga Institute of Dental Sciences, Campus 5, KIIT University, Bhubaneswar 751024, Odisha, India Tel +9l 9040324224

Email abikshyeet@yahoo.com

\begin{abstract}
The human jaw is an exclusive habitat for odontogenic lesions. Ghost cells associated odontogenic lesions are a diverse group with a variety of presentations in the jaws. Calcifying cystic odontogenic tumor is a benign cystic neoplasm of odontogenic origin which demonstrates ghost cells in the epithelial component. This tumor sometimes mimics the features of a cyst clinically and radiographically, but histopathologically as well as behavior-wise shows the features of a tumor. Many classification systems have been proposed and revised from time to time. Presently a dualistic concept is highlighted to classify this group of lesions. The present case highlights a case of calcifying cystic odontogenic tumor associated with a complex composite odontome, which appeared like a cyst clinically and radiographically.
\end{abstract}

Keywords: calcifying cystic odontogenic tumor, calcifying odontogenic cyst, odontome, ghost cell

\section{Introduction}

Calcifying cystic odontogenic tumor (CCOT) is a benign cystic neoplasm of odontogenic origin, characterized by an ameloblastoma-like epithelium with ghost cells that may calcify. ${ }^{1}$ Gorlin et al in 1962 first described this entity as calcifying odontogenic cyst (COC). ${ }^{2}$ Over the years since its first description, it has become clear that the COC has a number of variants, including features of benign odontogenic tumor. ${ }^{3}$ Because of the diversity in its clinical and histopathological features as well as in its biological behavior, there has been disagreement concerning the terminology used over the past several years. ${ }^{4}$ Patients with CCOT usually present with a slow-growing, asymptomatic swelling with hard bony expansion in case of intra-osseous lesions. Lingual expansion, displacement of teeth, and perforation of cortical plates are occasionally observed. ${ }^{5}$ Radiographically, all intra-osseous lesions appear as either uni- or occasionally multilocular radiolucencies. Irregular calcified bodies of varying size seen throughout the radiolucency are typical features. Larger radiopaque masses may be found in cases associated with odontoma. ${ }^{4}$ Histopathologically the most remarkable feature is the presence of ghost cells which have been compared with those found in the calcifying epithelioma of Malherbe in the skin. ${ }^{3}$ Individual ghost cells may fuse together to form large sheets of amorphous eosinophilic structures on which calcification may occur. Irregular masses of calcified structures suggestive of dysplastic dentin are present in association with basal layer. ${ }^{6}$ Occasionally these lesions are associated with formation of an area of hard dental tissue which resembles an odontome. ${ }^{5}$ This case report brings forth a case of CCOT associated with an odontome which was showing the diversified nature of such a lesion elaborately. 


\section{Case report}

A 25-year-old female patient presented with swelling in the mandible which had grown to its current size during the past year. Extraorally there is an obvious swelling noticed on the mandible extending from the right side of the body of the mandible to the left side, which was firm during palpation. Past medical and dental histories were non-contributory. On intraoral examination, there was a well-defined swelling extending from teeth number 36 to 45 measuring approximately $8 \times 3 \mathrm{~cm}$. Overlying mucosa was normal in appearance except for mucosa in relation to teeth number 33 to 35 , which was ulcerated (Figure 1). The swelling was hard on palpation. There is obvious obliteration of labial and buccal vestibules. Orthopantomogram revealed a well-defined radiolucency with scalloped border extending from 37 to 46 (Figure 2). Few areas were showing multiple foci of radiopacity. There was obvious evidence of root resorption of 37, 36, 35, 34, 33, 32, $31,41,42,43,44,45$, and 46 . An incisional biopsy was done and the histopathological examination revealed a connective tissue capsule lined by an epithelium which was composed of a well-defined basal layer of cuboidal cells with reversal of polarity. The superficial cells of the epithelium resembled stellate reticulum and within them numerous ghost cells were noticed. Based on the histopathology a diagnosis of COC was made. Surgical enucleation was performed. During enucleation a calcified mass resembling an odontome was also found associated with the capsule. After complete enucleation a bony window was left and an obturator was placed to maintain the bony window so as to ensure proper drainage and uneventful bone healing. The entire specimen was sent for histopathological examination. Multiple representative areas were obtained after grossing and processed. The calcified mass was subjected to decalcification. The cystic areas resembled the features

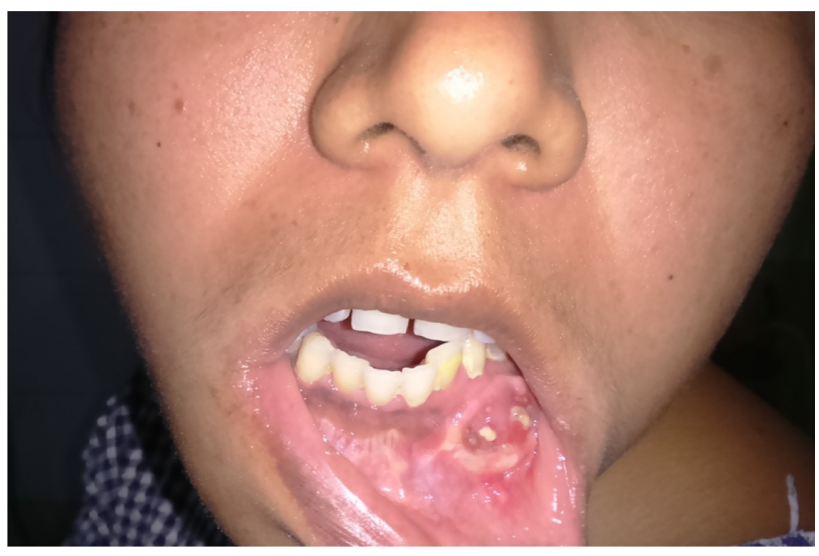

Figure I Intraoral view showing diffuse swelling of mandible with surface ulceration.

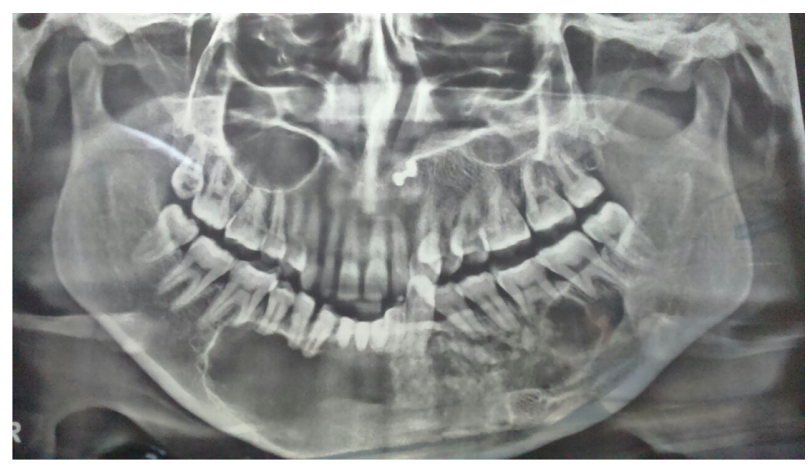

Figure 2 Orthopantomogram showing well-defined radiolucency with scalloped border.

Notes: Few areas showing multiple foci of radiopacity. There is obvious evidence of root resorption.

observed in the incisional biopsy specimen (Figure 3). But many areas also showed mural proliferation of epithelial islands resembling that of the lining (Figure 4). Evidence of calcification and dysplastic dentinoid formation was seen in the connective tissue adjacent to the epithelial islands. The calcified mass, upon decalcification, showed dentinoid with entrapped pulp-tissue-like structures (Figure 5). Numerous odontogenic epithelial islands were seen adjacent to the calcified mass and showed evidence of ghost cell formation and ghost cell calcification (Figure 6). The calcified mass resembled a complex composite odontome. Based on the lining, the evidence of mural proliferation in multiple areas and the odontome, a final diagnosis of CCOT associated with an odontome was made. The post-operative course was uneventful (Figure 7). An orthopantomogram was obtained 6 months later and showed evidence of new bone formation (Figure 8). The patient is currently under regular follow-up.

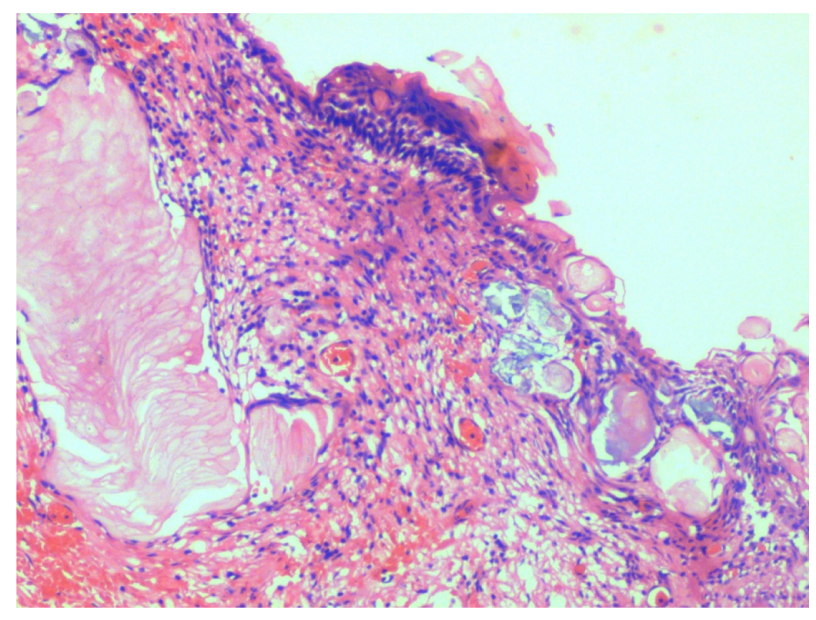

Figure 3 Cystic capsule lined with epithelium composed of a well-defined basal layer of cuboidal cells with reversal of polarity.

Notes: The superficial cells resemble stellate reticulum. Ghost cells present within the epithelium lining as well as inside the connective capsule. 


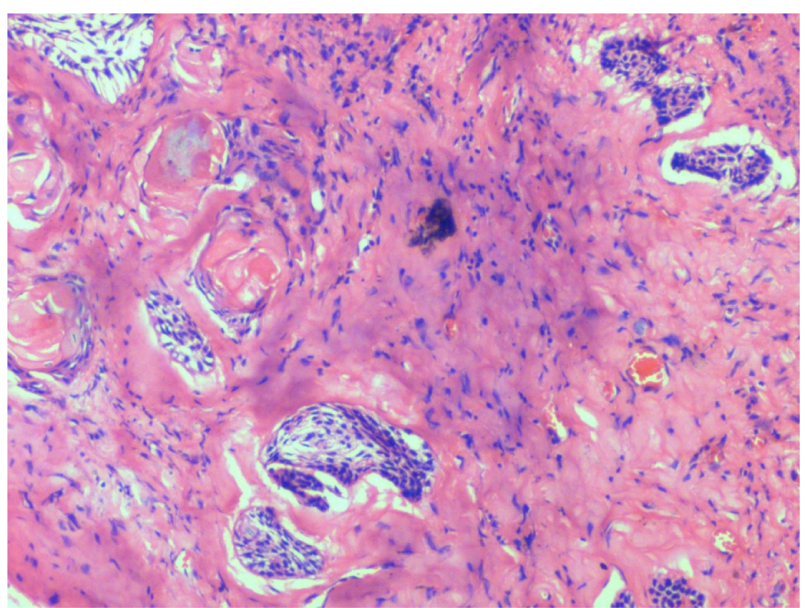

Figure 4 Mural proliferation of odontogenic epithelial islands.

\section{Discussion}

Over the years since its first description, it has become clear that the $\mathrm{COC}$ has a number of variants including features of a benign odontogenic tumor. ${ }^{3}$ Controversies and confusion never left this variety of lesions. ${ }^{4}$ Many names like COC (Gorlin et al), ${ }^{2}$ keratinizing COC, calcifying ghost cell odontogenic tumor, cystic calcifying odontogenic tumor, dentinogenic ghost cell tumor, epithelial odontogenic ghost cell tumor, odontogenic ghost cell tumor were proposed.? In 1971, the World Health Organization (WHO) described the lesion as a non-neoplastic cystic lesion and preferred to use the term COC. In 1992, WHO classified this lesion under odontogenic tumor but continued to use the term COC. In 2005, WHO renamed the lesion as CCOT. ${ }^{6}$

$\mathrm{COC} / \mathrm{CCOTs}$ are not very commonly encountered. The lesion occurs in a wide age range. The youngest recorded patient was 1-year-old; the oldest 82 years and there is an

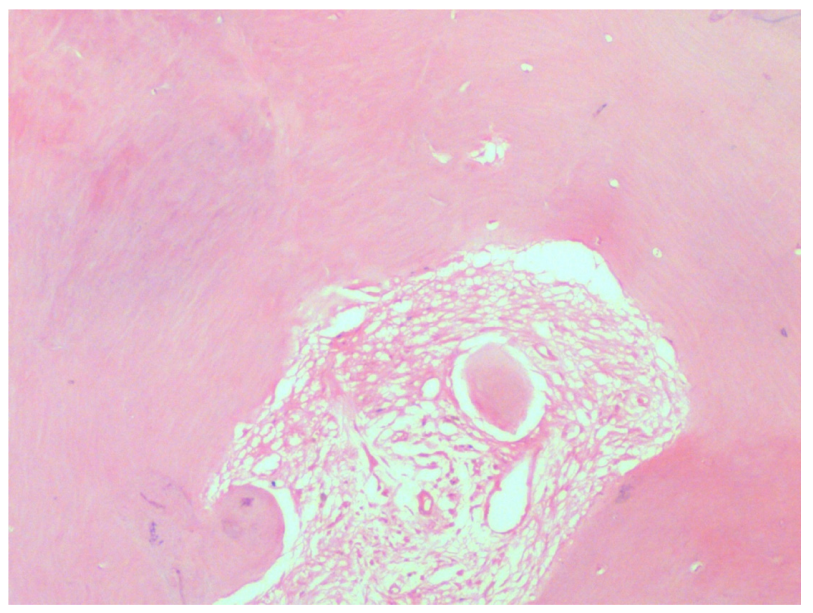

Figure 5 Odontome upon decalcification showing dentinoid with entrapped pulplike structures.

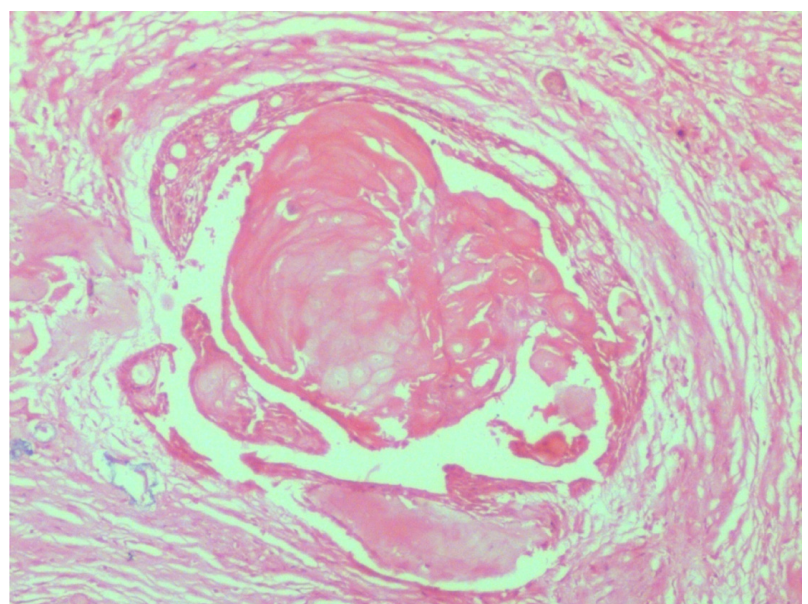

Figure 6 Odontogenic epithelial islands seen adjacent to the calcified mass showing evidence of ghost cell formation.

impressively high peak of patients who were in their second decade. There is a negligible difference in sex distribution and no racial predilection has been identified. ${ }^{3}$ CCOTs occur with equal frequency in the maxilla and mandible. ${ }^{8}$ It is predominantly an intra-osseous lesion, although $13 \%-30 \%$ of cases have appeared as peripheral (extraosseous) lesions. The cystic forms comprise $86 \%-98 \%$ of cases but the neoplastic variants are uncommon accounting for only $2 \%-16 \%$ of cases. ${ }^{9}$ Radiographically CCOTs are well delineated and appear as a unilocular or multilocular radiolucency with calcifications of variable density noted in one-third to half of cases. CCOTs can occur alone or in association with other odontogenic tumors such as odontomas, adenomatoid odontogenic tumors, and ameloblastomas. ${ }^{8}$ The roots of adjacent teeth are displaced or resorbed from the expansion of the lesion. The cortical bone is thinned, expanded or perforated. ${ }^{10}$ Histologic features include a cystic lining composed of an outer layer of a columnar basaloid odontogenic epithelium and an inner layer resembling stellate reticulum of the enamel organ. Characteristic features for

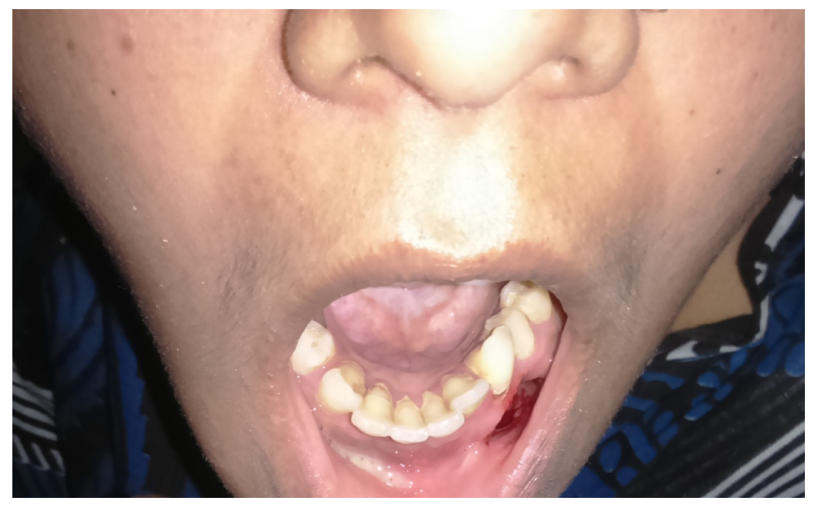

Figure 7 Intraoral view 15 days after surgery showing uneventful healing. 


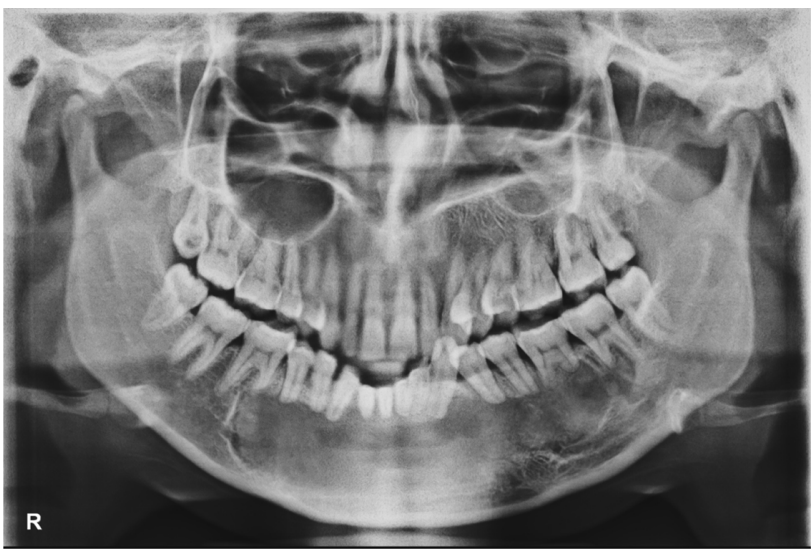

Figure 8 Orthopantomogram obtained 6 months post-operative shows evidence of new bone formation.

CCOT include the presence of ghost cells and/or calcifications within the cyst lining or fibrous capsule. ${ }^{8}$

In the present case the patient was in her third decade of life. The presentation was in the mandible. Radiographically the present case showed a large scalloped radiolucency with resorption of roots. Many radiopaque foci were also noticed. The pathology showed mural proliferation along the cyst wall capsule and was associated with a complex composite odontome.

Many classification systems have attempted to classify this diverse group of lesions. ${ }^{1,3,4,7} \mathrm{Toida}^{7}$ in his review summarized all the classification systems and he proposed a classification suitable for the group of lesions demonstrating ghost cells. He suggested a dualistic concept in order to describe these lesions which are segregated into two groups. A cystic group and a neoplastic group. But Toida also expressed his concern over classifying a lesion showing cystic architecture under a cystic or neoplastic group. ${ }^{7}$ The present case truly justifies his concern as it shows a cystic architecture, a mural proliferation, and association of an odontome.

Many authors have recently outlined a variety of lesions having diverse presentations. Aithal et al presented a case which they diagnosed as ameloblastomatous COC. They reported the presence of a cystic lining along with acanthomatous ameloblastic islands in the connective tissue. ${ }^{11}$ Iida et al reported a case of ameloblastomatous $\mathrm{COC}$ which showed presence of $\mathrm{COC}$ with solid parts of ghost cells, and ameloblastomatous proliferation in the connective tissue of the cyst wall. ${ }^{12}$ Kamboj and Juneja also reported a similar case of ameloblastomatous Gorlin's cyst which showed intraluminal and intramural proliferation of ameloblastomatous follicles with a few follicles showing ghost cells. Juxta epithelial dentinoid formation was also reported. ${ }^{13}$ Singhaniya et al reported a case of a dentinogenic ghost cell tumor which showed many foreign body types of giant cells associated with the lesion. ${ }^{14}$ Manveen et al reported a case of CCOT which was mimicking a residual cyst clinically and radiographically. ${ }^{5}$

The present case invokes a lot of interest as this CCOT is showing all the features of a tumor histopathologically, but clinically and radiographically looking like a cyst. Surgical intervention yielded a cystic mass which upon histopathological examination revealed its neoplastic nature. The present case also highlights the presence of a complex composite odontome associated with the lesion. All these features make this lesion a diverse entity. The present case strengthens the dualistic concept proposed for the classification of ghost cell related lesions and invokes interest to study similar pathologies and their behavior to strengthen the clinical acumen.

\section{Disclosure}

The authors report no conflicts of interest in this work.

\section{References}

1. Praetorius F, Ledesma-Montes C. Calcifying cystic odontogenic tumor. In: Barnes L, Eveson JW, Reichart P, Sidransky D, editors. WHO Classification of Tumors. Pathology and Genetics of Head and Neck Tumors. Lyon: WHO IARC; 2005:313.

2. Gorlin RJ, Pindborg JJ, Odont, Clausen FP, Vickers RA. The calcifying odontogenic cyst - a possible analogue of the cutaneous calcifying epithelioma of Malherbe. An analysis of fifteen cases. Oral Surg Oral Med Oral Pathol. 1962;15:1235-1243.

3. Shear M, Speight P. Calcifying odontogenic cyst (calcifying cystic odontogenic tumor). In: Shear M, Speight P. Cysts of the Oral and Maxillofacial Regions. 4th ed. Blackwell Munksgaard; 2007:100-107.

4. Reichart PA, Philipsen HP. Calcifying Ghost cell Odontogenic Cysts/ Tumors (odontogenic Ghost Cell Lesions). In: Reichart PA, Philipsen HP. Odontogenic Tumors and Allied Lesions. 1st ed. London: Quintessesnce Publishing Co; 2004:69-77.

5. Manveen JK, Subramanyam RV, Ramandeep NS. Calcifying Cystic Odontogenic Tumour Mimicking As A Residual Cyst. Journal of Clinical and Diagnostic Research. 2010;(4):2979-2983.

6. Thinakaran M, Sivakumar P, Ramalingam S, Jeddy N, Balaguhan S. Calcifying ghost cell odontogenic cyst: A review on terminologies and classifications. J Oral Maxillofac Pathol. 2012;16(3):450-453.

7. Toida M. So-called calcifying odontogenic cyst: review and discussion on the terminology and classification. J Oral Pathol Med. 1998;27(2): 49-52.

8. Zornosa X, Müller S. Calcifying cystic odontogenic tumor. Head Neck Pathol. 2010;4(4):292-294.

9. Neville BW, Damm DD, Allen CM, Bouquot JE. Oral and Maxillofacial Pathology. 3rd ed. Philadelphia: Saunders; 2004.

10. Kler S, Palaskar S, Shetty VP, Bhushan A. Intraosseous calcifying cystic odontogenic tumor. J Oral Maxillofac Pathol. 2009;13(1):27-29.

11. Aithal D, Reddy BS, Mahajan S, Boaz K, Kamboj M. Ameloblastomatous calcifying odontogenic cyst: a rare histologic variant. J Oral Pathol Med. 2003;32(6):376-378.

12. Iida S, Ueda T, Aikawa T, Kishino M, Okura M, Kogo M. Ameloblastomatous calcifying odontogenic cyst in the mandible. Dentomaxillofac Radiol. 2004;33(6):409-412.

13. Kamboj M, Juneja M. Ameloblastomatous Gorlin's cyst. J Oral Sci. 2007;49(4):319-323.

14. Singhaniya SB, Barpande SR, Bhavthankar JD. Dentinogenic ghost cell tumor. J Oral Maxillofac Pathol. 2009;13(2):97-100. 
Clinical, Cosmetic and Investigational Dentistry

Dovepress

\section{Publish your work in this journal}

Clinical, Cosmetic and Investigational Dentistry is an international, peer-reviewed, open access, online journal focusing on the latest clinical and experimental research in dentistry with specific emphasis on cosmetic interventions. Innovative developments in dental materials, techniques and devices that improve outcomes and patient satisfac-

tion and preference will be highlighted. The manuscript management system is completely online and includes a very quick and fair peerreview system, which is all easy to use. Visit http://www.dovepress. com/testimonials.php to read real quotes from published authors.

Submit your manuscript here: http://www.dovepress.com/clinical-cosmetic-and-investigational-dentistry-journal 